\section{Allergy $_{\text {and }}$ Immunology}

\title{
Associate Editor Martin Röllinghoff
}

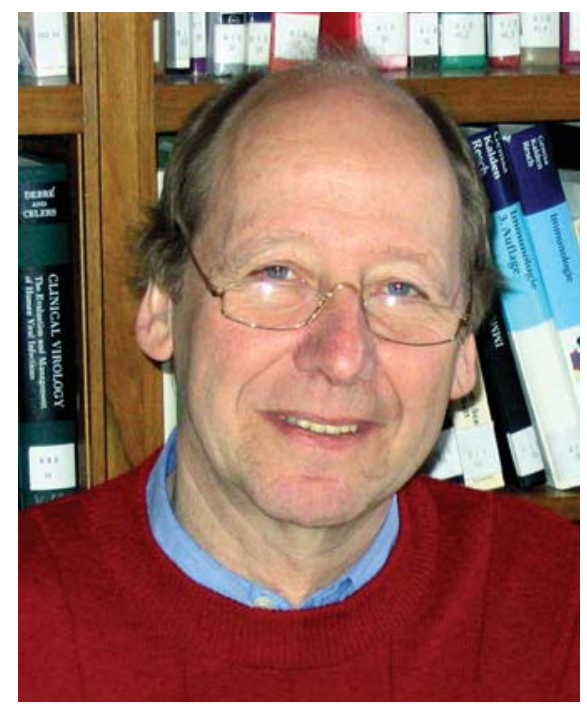

Martin Röllinghoff, Erlangen.
Martin Röllinghoff has made himself known by contributions to immunology. His early studies in Mainz were in the field of complement, and in Melbourne, he analyzed the effect of T-lymphocytes in response to tumors. Back in Mainz, he contributed to studies related to the biological role of cytokines and a cytokine now designated interleukin 2. In Erlangen, his interest changed from immunology to microbes. Together with his coworkers, he obtained new information on the immune response to yersinia, mycobacteria tuberculosis, candida, and, in particular, to the protozoa Leishmania. The studies to Leishmania were performed in a mouse model, which allowed decisive experiments concerning the cause of the different courses of benign cutaneous leishmaniasis (oriental sore) and fatale visceral leishmaniasis (kalaazar) as well as persistence of the parasite. 